\title{
Primary Health Care Research and Development.
}

Title:-

Evaluation of a Brief Intervention to Assist Health Visitors and Community Practitioners to Engage with Fathers as Part of the Healthy Child Initiative

\section{AUTHORS:}

Heatha Humphries

Research Associate

Institute of Health \& Society

University of Worcester

Current Appointment: Research Associate, University of Leicester

Qualifications: PhD

\section{Mary Nolan}

Professor of Perinatal Education

Institute of Health \& Society

University of Worcester

Current Appointment: Professor of Perinatal Education, University of Worcester

Qualifications: PhD, MA, BA (Hons.), RGN

\section{ABSTRACT}

Aims:

To improve engagement with fathers of Health Visitors and Community Practitioners delivering the Healthy Child Programme.

To evaluate a one-day, father-focused workshop with supporting handbook for Practitioners.

To identify institutional and organisational barriers to engagement with fathers.

Background:

UK government policy encourages health professionals to engage with fathers. This derives from robust evidence that fathers' early involvement with their children impacts positively on emotional, behavioural and educational development. Yet there is little evidence that the importance of engaging fathers is reflected in Health Visitor training or that primary care services are wholly embracing father-inclusive practice. The Fatherhood Institute (FI), a UK charity, has developed a workshop for Practitioners delivering the Healthy Child Programme.

Method:

A 'before and after' evaluation study, comprising a survey followed by telephone interviews, evaluated the impact of the FI workshop on Health Visitors' and Community Practitioners' knowledge, attitudes and behaviour in practice. A total of 134 Health Visitors and Community 
Practitioners from 8 NHS Trusts in England attended the workshop from November 2011 to January 2014 at 12 sites. A specially constructed survey, incorporating a validated questionnaire (Palkovitz, 1984) was administered prior to the workshop, immediately afterwards and three months later. Telephone interviews further explored participants' responses.

Findings:

Analysis of questionnaire data showed that the workshop and handbook improved participants' knowledge, attitudes and behaviour in practice. This was sustained over a three month period. In telephone interviews, most participants said that the workshop had raised their awareness of engaging fathers and offered them helpful strategies. However, they also spoke of barriers to engagement with fathers. NHS Trusts need to review training and education of Health Visitors and Community Practitioners and take a more strategic approach to father-inclusive practice and extending services to meet the needs of fathers.

\section{Background}

UK national policy (e.g. Department of Health, DH, 2009; DH, 2014) enshrines commitment to developing universal, father-inclusive family services. Yet studies both from the UK and across the world suggest that the needs of men as they make the transition to fatherhood are not being met, nor are they clearly understood. Common barriers to better engagement with fathers have been identified, including a predominantly female health and family care workforce (Lamour \& Letronnier, 2003; Page \& Whitting, 2008), lack of confidence on the part of practitioners to engage with fathers (Shribman \& Billingham, 2008), practitioners not seeing it as their remit to work with fathers (Zanoni et al., 2013), outdated ideas about babies' attachment being solely to the mother (Taylor \& Daniel, 2000), prejudiced attitudes towards men as fathers (Sherriff \& Hall, 2011), paucity of information specifically directed at fathers (Steen et al., 2012) and negative images of fathers displayed in public service settings (McMaster et al., 2014). Maternity services being described as 'woman-centred', rather than 'family-centred' as advised by McKellar et al. (2008) and discriminatory use of the word 'parent' in family services to mean 'mother' and not 'mother and father' also make it less likely that family practitioners will engage with fathers or fathers with practitioners.

Yet a significant body of evidence supports the importance of fathers' positive, active involvement with their children. This has been shown to enhance children's educational attainment (Yogman \& Kindlon, 1995; Aldous \& Mulligan, 2002) and reduce emotional and behavioural problems (Ramchandani et al., 2013). Fathers can act as a 'buffer' against the potentially negative effects on children of a mother's postnatal depression (Chang et al., 2007) and are an important influence on the mother's decision to breastfeed and to continue breastfeeding (Everett et al., 2006; Tohotoa et al., 2009; Sherriff \& Hall, 2011).

Studies with fathers frequently report that fathers feel overlooked (StGeorge \& Fletcher, 2011) or invisible and insulted around the time of the birth of their baby and during the postnatal period (Salzmann-Erikson \& Eriksson, 2013: 385) resulting in feelings of helplessness (Backstrom \& Hertfelt Wahn, 2011) and isolation (Deave et al., 2008). The UK Fatherhood Institute's report, The Cost and Benefits of Active Fatherhood (2008) notes that family practitioners often approach father-child relationships at best casually and, at worst, with hostility. 
The consensus in the literature is that fathers are underused as a source of support for their children (Fisher, 2007); that 'healthcare professionals, especially midwives and health visitors, are well placed to support expectant and new fathers' (Deave \& Johnson, 2008: 632), and that services must develop new ways of reaching out to men (Plantin et al., 2011). Fathers want support from health and family care professionals (Garfield \& Isacco, 2012). However, those professionals need to feel positive and confident about engaging with fathers (Magill-Evans et al., 2006) and this is likely to come from specific education and training to help them address their fear of engaging men and improve communication (Cowley et al., 2013; Zanoni et al., 2013). It was with a view to contributing to the development of effective training and support for family professionals that the current study to evaluate a one-day workshop and handbook was undertaken.

\section{METHODS}

Intervention

The intervention was a one-day workshop for practitioners, particularly Health Visitors, engaged in delivering the Healthy Child Programme. Designed to help participants develop and implement a whole-team approach to engaging with fathers, the workshop agenda included discussion of 'stereotypes and assumptions'; a presentation of the research around fathers' impact on maternal health and child development; time for reflection on participants' own experiences of being 'fathered'; how to engage with fathers in separated families, and developing systematic approaches to engaging with fathers. The workshop was delivered by facilitators from The Fatherhood Institute and supported by a handbook entitled, Health Visitors and Fathers: a Good Practice Guide, which reinforced its content and key messages.

\section{Study Design}

The study employed a 'before and after' evaluation design, with each group of participants completing a questionnaire at the start of the workshop, immediately on completion, and an online questionnaire three months later. Participants who consented to be contacted by telephone after completing the three month questionnaire were interviewed using an interview schedule designed, following analysis of the questionnaires, to explore key issues further. The study comprised a pilot phase conducted with nine Health Visitors who attended the workshop at one site, followed by the main phase. Data was collected over a 27 month period. The pilot study aimed to identify any difficulties with the wording of the questionnaires, with the content of the handbook and with the process of distributing and collecting the three questionnaires. Following scrutiny of the pilot process and of the data obtained, minor amendments were made to the content of the handbook, and a change of data collection method was implemented for the three month questionnaire, from post to online (via Survey Monkey) in order to improve the response rate.

The Fatherhood Institute (FI) invited NHS Trusts throughout England to host the workshop and 8 agreed. The workshop was delivered at 12 sites from Devon to Tyneside. Information about the workshop was given to Health Visitors and Community Practitioners via emails, meetings and notice boards by local collaborators appointed at each study site to recruit workshop participants. Once recruitment was complete (maximum 20 people per site) a Study Information 
Sheet was emailed to participants one week before the workshop. Each workshop was facilitated by a trainer from the $\mathrm{Fl}$ and followed the same timetable. A member of the research team ( $\mathrm{HH}$ or $\mathrm{MN}$ ) distributed and collected the questionnaires at the beginning and end of the workshop. Fifteen minutes were set aside for the questionnaires to be completed on each occasion. The workshop facilitators did not see any participant's questionnaires. Three months' later, the third questionnaire was emailed to workshop participants by one of the researchers $(\mathrm{HH})$ via Survey Monkey). Non responders were sent two email reminders. Once data collection across all sites was completed and the data analysed, participants who showed substantial changes in attitudes and practice behaviour across the three questionnaires were identified and invited to give a telephone interview. $\mathrm{HH}$ carried out these interviews, using a semi structured interview schedule designed to explore the questionnaire data further. All interviews were transcribed and the two authors independently identified, and then agreed, the most frequently mentioned topics.

Participants

During the Pilot Study and Year 1, participants were restricted to qualified Health Visitors. In Year 2, an amendment was made to the protocol to include student Health Visitors, Family Practitioners and Community Nursery Nurses who were working with families and young babies as these professionals frequently attended the workshops. In total, 191 people attended the 12 workshops, and 134 (70\%) took part in the evaluation. This discrepancy was partly due to non Health Visitors not being invited to participate in the early stages of the study, and to three people leaving during the workshop. Socio-demographic data for participants is summarised in Table 1.

Table 1

Most participants $(49 ; 36.6 \%)$ were within the $40-49$ years age range and female $(131 ; 97.8 \%)$. The majority were practising Health Visitors (110; 82.1\%), although this is likely to have been influenced by the initial recruitment strategy, which only targeted practising Health Visitors to the exclusion of other practitioners. The amount of time for which participants had worked with families in the community ranged from 1 month to 37 years, with a mean of 8 years and 4 months and median of 4 months. These figures are likely to have been affected by the inclusion of practising student Health Visitors and other Community Practitioners in Year 2 of the study.

\section{Measures: Questionnaires}

The questionnaires were divided into three sections to obtain information about participants' knowledge (Section 1), their attitudes towards fathers of young children (Section 2) and their practice behaviour and intentions (Section 3).

The first section comprised eight questions designed by the research team and the $\mathrm{Fl}$ to gain a broad overview of participants' knowledge of the level of involvement of UK fathers in the lives of their children and of the impact of fathers on their children's and partners' health and wellbeing. The questions were derived from work completed by The Fatherhood Institute (2008; 2010) and from the literature. An example is:

In a study of two-parent families across four ethnic groups in England, it was found that fathers have a particularly important role to play in which ONE of the following activities? 
Playing with their children

Disciplining their children

Physical care-giving

Being a confidante for their children

Unsure / Don't know

The second section explored workshop participants' attitudes towards fathers using the Role of the Father Questionnaire (ROFQ) (Palkovitz, 1980, 1984). The validity of this questionnaire, which measures perceptions of the importance of the father's role in caring for children, has previously been tested with a parent population. It was felt that it could equally be used to measure health professionals' perceptions of the father's role. The ROFQ contains 15 statements, such as:

The way a father treats his baby in the first six months has important lifelong effects on the child.

Respondents were asked to indicate their level of agreement with each item on a 5 point Likert scale ranging from 'strongly agree' to 'strongly disagree'. Higher scores reflect attitudes that fathers are capable parents and sensitive to their children.

The third section was designed to ascertain the extent to which study participants were currently engaged with the fathers of families that they were visiting (questionnaire at start of workshop); intended to engage with them (questionnaire at end of workshop) and had engaged with them (questionnaire 3 months post workshop). Respondents were asked to answer yes, no or uncertain to each of 13 statements, such as:

I always ask fathers to be present the first time I meet a family and agree a convenient time when they can be there ( $1^{\text {st }}$ questionnaire)

The maximum score for Section 1 was 19; for Section 2, 75 and for Section 3, 26.

Telephone Interview

The semi structured telephone interview schedule was devised by the research team, following analysis of the questionnaire data, to explore participants' responses further, as well as their evaluation of the workshop and handbook.

Ethics

Permission to carry out the study was granted by a University Ethics Committee and each participating Trust granted ethical permission via its Research \& Development Office.

A member of the research team ( $\mathrm{HH}$ or $\mathrm{MN}$ ) received written informed consent from each participant at the start of the workshop, following the opportunity to ask questions about the study. Participants had received the Study Information Leaflet prior to the workshop. Assurances were given that everyone had the right to decline to take part in the study, that responses would be seen only by the researchers and that published data would be anonymous. Permission to record the telephone interview was given verbally over the phone and subsequently recorded. 


\section{DATA ANALYSIS}

Data was entered into SPSS, Version 21. Non parametric analysis of data from the pilot and main study phases combined was undertaken using the Friedman Test to identify changes in participants' scores across the three time periods. Where statistically significant differences were identified, a further ad-hoc test was employed and the Wilcoxon Signed Rank Test was used to measure any change in pre-workshop knowledge, attitudes and behaviour in practice in the short term (i.e. by the end of the study day) and longer term (i.e. 3 months' later).

Using a line graph to observe directionality of change in responses for Sections 2 and 3 (attitudes and behaviour in practice) across the three questionnaires, participants were purposively invited for telephone interview if they demonstrated a substantial change in attitudes and/or practice during the three month period following attendance at the workshop.

The interviews were subjected to thematic analysis by the two authors working independently; findings were then compared and agreement reached.

RESULTS: Questionnaires

Response rates for the questionnaires are reported, per site, in Table 2.

\section{Table 2}

The median scores per section of the questionnaire, at each of the three time points, are reported in Table 3.

Table 3

The results of the Friedman Test indicated that there was a statistically significant difference in knowledge scores across the three questionnaires $\left(\chi^{2}(2, n=80)=52.993, p<.001\right)$; in attitude scores $\left(\chi^{2}(2, n=83)=34.995, p<.001\right)$ and behaviour in practice scores $\left(\chi^{2}(2, n=80)=91.684, p\right.$ $<.001)$.

Post hoc analysis using the Wilcoxon Signed Ranks test determined where the specific differences lay. A Bonferroni correction was applied to the initial $\alpha=.05$, for the post hoc analyses, resulting in an adjusted significance level of .017 to account for the increased risk of a Type I error.

In summary, the analyses showed statistically significant improvements in knowledge, more positive attitudes towards fathers and heightened commitment to engaging fathers in practice (behaviour) from the beginning to the end of the workshop (questionnaires 1 and 2) with moderate to strong effect sizes. However, scores decreased in the next three months, from completing questionnaire 2 to 3 . The decline was statistically significant for knowledge (with a small effect size $r=.23$ ) and behaviour in practice (with a moderate to strong effect size $r=.43$ ) but not significant for attitudes (with a small effect size of $r=.14$ ). Overall, however, results were statistically significant between questionnaires 1 and 3, with small to moderate effect sizes, indicating that learning was sustained over the three month study period. 


\section{Open-Ended Questions}

When completing the three month questionnaire, participants were invited to comment on what they had found most and least useful about the workshop and handbook. Nearly all the participants $(83 ; 95.4 \%)$ took this opportunity to comment positively on the workshop, with very few dissenting voices. The five most frequently mentioned helpful aspects of the workshops are illustrated below with extracts from the questionnaire responses.

\section{a) Raised awareness}

(The workshop) helped to raise my awareness of the importance of engaging with Fathers and supporting and encouraging them to be involved in their child's physical and emotional care.

Increased awareness of how invisible fathers can be made to feel at times.

Some participants commented on how increased awareness had changed their practice, during the three months since the workshop:

I now have increased awareness about the needs of fathers and ensure that they are included as much as the mother during home visits.

A few participants felt that they had learned nothing of value as engaging fathers was already part of their practice:

A lot of the content was not new to us and as practitioners we are convinced of the necessity to engage fathers.

b) Understanding the research evidence

For many study participants, receiving information about current research was affirming:

The research and quotes from parents were very useful - backs up my thoughts re including fathers more consistently.

c) Learning practical strategies for engaging fathers

Many of the participants wrote about how useful it was to be told about proven strategies for engaging fathers:

Ensuring letters addressed to both parents and making a point of trying to make sure they (fathers) are also at home for visits.

How to engage with fathers more, to include them and speak to them more on visits, rather than aiming everything at the mother, which I was probably doing before. 
One respondent was inspired to innovate in her practice:

Following the study day, we started a nature walking group which was aimed at both Fathers and whole families. Initial attendance of fathers has been good.

d) Sharing knowledge

For some practitioners, the workshop provided a rare and valuable opportunity to talk to others and share their knowledge and experiences:

It was good to network with other professionals and listen to others' views on the subject.

\section{e) Reflecting on current services}

Some participants noted that the workshop had highlighted limitations in their practice, and expressed frustration at not being able to engage fathers owing to restrictions imposed by the service they worked in:

All staff in all multidisciplinary teams should access training in this area. Despite utilising tools suggested to engage fathers, we are still not effective. More work needs to be done on why this is and men still feel alienated and excluded in the upbringing of their children - staff need to be more flexible towards fathers ie offering later appointments/preparation for parenthood classes in the evenings and not just sticking to the traditional health visiting hours of 9 to 5.

What we need is the strategic interventions that will support us to achieve change.

Unfortunately, due to the pressures of low staffing we are unable to do any extra work at present. We don't have any control over displays and information that is available to give out. Fathers have often returned to work by the time we visit and engaging them with our service is still difficult.

\section{Further training}

Participants were asked about their perceived need for further training. No further training was felt to be needed by $54(64.3 \%)$ respondents while $30(39.2 \%)$ felt that they did need more:

In accordance to the Healthy Child Programme, offering father equality in service provision is essential. Therefore I believe that ongoing training opportunities which highlight continuing need and promote development of skills are essential.

\section{TELEPHONE INTERVIEWS}

Participants from the main study who completed all three questionnaires $(n=75)$ were considered for interview. Of these, ten had incomplete data and six had stated on their third questionnaire that they did not wish to be interviewed. Of the fifty-nine remaining participants, 
54 demonstrated a substantial change in attitudes and behaviour across the three questionnaires, using a line graph to observe directionality of change, and all of these were invited to be interviewed. Twenty-six agreed with the remainder either failing to respond to the email invitation, being impossible to contact or when contacted, citing workload pressures as prohibiting their involvement. Interviewees came from all study-sites bar one where the only person to complete all three questionnaires declined to be interviewed. The interviews were transcribed and thematic analysis identified three key areas of concern. Quotations have been selected from across the participants.

a) Participants' perceptions of fathers

Several participants commented that fathers often seemed disinterested when they made home visits:

The dads kind of leave the room and leave the mums to it or go and walk the dog or smoke in the garden or something.

Prior to the workshop, some had interpreted this as fathers not wanting to be involved but now saw the situation differently:

I'd made an assumption that they weren't that bothered about being included whereas now I don't feel that way.

Participants found great satisfaction in improving their relationship with fathers:

Most fathers do want to engage and they look absolutely delighted when you do. Really it's quite shameful because you're just treating them the same as the mothers and it's quite shameful when you do look back at your practice and you see the difference that it has made.

b) Difficulties accessing fathers

Many participants commented that they didn't engage with fathers because the fathers were at work when they visited. Some were prepared to acknowledge that their service was really not as client centred as we could be. Some participants talked about how simple measures could make their service more available to fathers:

I think it's really important to give the dads a little bit extra time or giving them some notice so that they can get time off work if that's needed.

Maybe promoting ourselves to dads more and making them realise it's a family thing not just a mum thing and then they might be able to be there more often if work would allow it.

c) Obstacles to father inclusive practice

There was recognition that barriers were created by health visiting being almost exclusively a female profession:

Maybe they would be different if it was a male trying to talk to them. So maybe it's their preconceived ideas about who can help them and who can't. 
One participant explored this more fully,

Having conversations with fathers is quite different to having conversations with mothers. I mean traditionally, we've been maternal and child health services. We're very used to talking with women. Most of us are women so we relate woman to woman in a very different way and that's an interesting scenario.

Concerns were voiced about systems for recording information which hadn't been updated to include fathers, so that children's records and routine letters referred only to mothers. Some felt that barriers to father inclusive practice were at ground level:

There seems to be an emphasis about reaching out to dads but it hasn't quite filtered down into practice perhaps as well as it possibly could.

Others felt there was a lack of support from managers and leaders:

I don't think you will see real changes in numbers of fathers who feel fully engaged until we've done more strategic work and that we've got stakeholders who can influence it.

It was generally recognised that there needed to be a shift in culture and therefore, that changes in practice were not going to happen immediately. However, one participant was optimistic:

I think the way the service is moving is towards engaging the whole family.

\section{DISCUSSION}

This study found that a one-day workshop dedicated to father-inclusive practice, designed and delivered by a charity with extensive knowledge of fatherhood research and training expertise, impacted positively on participants' knowledge of and attitudes towards fathers, and their behaviour in practice. Improvements in these areas occurred not only during the workshop, but were largely sustained over a three month period. The Healthy Child Programme (DH, 2009) aims to increase rates of initiation and continuation of breastfeeding, enhance the emotional and social wellbeing of children, improve their early learning and ensure they are ready for school. It is known that positive involvement of fathers with their children from babyhood can assist in meeting all these targets (Sherriff \& Hall, 2014; Ramchandani et al., 2013; Yogman \& Kindlon, 1995; Aldous \& Mulligan, 2002, respectively). Fathers need support during the early years of their children's lives, just as mothers do. In order to provide this support, health visitors must ensure that contact with the family routinely involves and supports fathers, including nonresident fathers (Healthy Child Programme, 2004:10).

A substantial number of participants in this study felt there was a need for dedicated training to enable them to feel more confident about engaging with fathers and to learn proven strategies to help them achieve this. Scores improved significantly from questionnaire one when participants rated their current level of engagement with fathers, to questionnaire two when they rated their future intention to engage with fathers. However, a statistically significant downturn in scores between the second and three month questionnaire, when participants reflected on how successful they had been in realising their intention, suggests that there are obstacles to putting learning into practice, even though improvements were sustained overall. 
Responses to the open ended questions and the telephone interviews illuminated challenges faced by family practitioners, despite their optimism (and intentionality) at the end of the workshop to engage with fathers. Participants identified barriers that have long been recognised in the literature, for example: that health visiting is a predominantly female workforce (Lamour \& Letronnier, 2003; Page \& Whitting, 2008), that services have been focused solely on mothers for a long time (Shribman \& Billingham, 2008), that this has resulted in fathers' expecting to be excluded (Taylor \& Daniel, 2000) and a lack of commitment at a senior level to mainstreaming father inclusive practice (Page \& Whitting, 2008). The majority of participants identified problems contacting fathers due to overlap between their own and fathers' working hours. Fathers were reported to be frequently unavailable having returned to work after paternity leave. Taylor \& Daniel (2000) advise that Health Visitors should raise this as an issue at organisational level, so that out of hours' provision can be made to capture as many fathers as possible.

The strength of the study lies in the range of geographical locations where the workshop was offered, thus enabling its impact on Health Visitors practising in varied communities to be assessed. In order to eliminate bias, the workshop facilitators were at no point involved in analysing any of the data. The study's longitudinal design enabled the impact of the workshop to be considered over a three month period, thereby offering greater security that learning derived from it was indeed being implemented in practice. However, it is a limitation of the study that further data collection was not carried out at a later date to enable assessment of the workshop's longer-term impact on practice. Funding did not allow for the study-period to be prolonged. In addition, while the workshop hoped to assist the development of a whole-team approach to father-inclusive practice, the current evaluation addressed only its impact on individuals. Individuals may find it hard to change their practice if other members of the team are resistant or disinterested. The impact of the workshop might have been more fully evaluated had it been possible to undertake focus groups with teams that included an individual who had attended the workshop, or to have carried out a case-study of one particular team following attendance by one or more members at the workshop.

\section{CONCLUSION}

The participants in this study considered that the workshop run by the Fatherhood Institute was timely, relevant and practical. However, the study findings emphasise the difficulties faced by practitioners when they attempt to implement training in practice. Participants identified organisational and cultural barriers, as well as resistance from colleagues, to father-inclusive practice and felt that it was beyond their remit to address such issues. This resonates with other studies which have explored the gap between evidence and practice, such as Metcalfe et al. (2001) who, like the Health Visitors in this study, identified insufficient time, inadequate facilities and isolation from colleagues as barriers, and Bailey et al. (2003) who also identified lack of time along with difficulties in integrating a new approach within the multi-disciplinary team. Tansella and Thornicroft (2009:284) note that, 'The sustainability of clear expectations and incentives for practitioners requires a series of behavioural and organisational mechanisms to be deployed in a coordinated way'. It would therefore seem important for whole teams, as well as managers and professional leaders, to attend the FI training or similar, in order to address the infra-structure inhibiting father-inclusive practice. As health services in the UK and across the world confront escalating costs, the potential for brief interventions to bring about lasting changes in qualified practitioners' attitudes and capacity to engage with fathers requires exploitation. The way forward may be to define continuing professional development as a whole team activity rather than an individual one. 


\section{REFERENCES}

Aldous, J. and Mulligan, G.M. 2002: Fathers' child care and children's behaviour problems: a longitudinal study. Journal of Family Issues 23, (5), 624-647.

Backstrom, C. and Hertfelt Wahn, E. 2011: support during labour: first-time fathers' descriptions of requested and received support during the birth of their child. Midwifery 27, (1), 67-73.

Bailey, R., Burbach, F. and Lea, S. 2003:the ability of staff trained in family interventions to implement the approach in routine clinical practice. Journal of Mental Health 12, (2), 131-141.

Chang, J., Halpern, C., Kaufman, J. 2007: Maternal depressive symptoms, father's involvement, and the trajectories of child problem behaviors in a US national sample. Archives of Pediatric Adolescent Medicine 161, 697-703.

Cowley, S., Whittaker, K., Grigulis, A., Malone, M., Donetto, S., Wood, H., Morrow, E., Maben, J.2013: Why Health Visiting? A review of the literature about key health visitor interventions, processes and outcomes for children and families. (Department of Health Policy Research Programme, ref. 0160058). London: Kings College London.

Deave, T. and Johnson, D. 2008: The transition to parenthood: what does it mean for fathers? Journal of Advanced Nursing 63, (6), 626-633

Deave, T., Johnson, J., Ingram, J. 2008: Transition to parenthood: the needs of parents in pregnancy and early parenthood. BMC Pregnancy and Childbirth.

Available at: http://www.biomedcentral.com/1471-2393/8/30.

Department of Health 2009: Healthy Child Programme: pregnancy and the first five years of life. Available at:

http://www.dh.gov.uk/en/Publicationsandstatistics/Publications/PublicationsPolicyAndGuidanc e/DH 107563

Department of Health 2014: Overview of the six early years high impact areas.

Available at:

https://www.gov.uk/government/uploads/system/uploads/attachment data/file/326888/Early Years Impact Overview.pdf

Everett K.D., Bullock L., Gage J.D., Longo D.R., Geden E., Madsen R. 2006: Health risk behaviour of rural low-income fathers. Public Health Nursing 23, (4), 297-306.

Fisher, M. 2007: The invisible parent. Nursing Standard 21, (41), 26-27.

Garfield, C.F. and Isacco, A.J. 2012: Urban fathers' involvement in their child's health and healthcare. Psychology of Men and Masculinity 13, (1), 32-48.

Lamour, M. and Letronnier, P. 2003: Prevention of fatherhood disorders - accompanying early father-child interaction in day-care centers. European Journal of Psychology of Education 18 (2), 191-210.

Magill-Evans, J., Harrison, M.J., Rempel, G., Slater, L. 2006: Interventions with fathers of young children: systematic literature review. Journal of Advanced Nursing 55, (2), 248-264. 
McKellar L., Pincombe J., Henderson A. 2008: Enhancing fathers' educational experiences during the early postnatal period. The Journal of Perinatal Education 17, (4), 12-20.

McMaster A., Ibrahim R., McLean S. 2014: Are fathers getting a confused message? International Journal of Birth and Parent Education, 1, (3), 35-36.

Metcalfe, C., Lewin, R., Wisher, S., Perry, S., Bannigan, K. and Klaber Moffett J. 2001: Barriers to implementing the evidence base in four NHS therapies: dietitians, occupational therapists, physiotherapists, speech and language therapists. Physiotherapy, 87, (8), 433-441.

Page, J. and Whitting, G. 2008: A review of how fathers can be better recognised and supported through DCSF policy. (Research Report DCSF-RR040). London: DCSF.

Palkovitz, R. 1980: Predictors of involvement in first-time fathers. Dissertation Abstracts International, 40, 3603b-3604b (University Microfilms No 8105035)

Palkovitz, R. 1984: Parental attitudes and fathers' interactions with their five month old infants. Developmental Psychology 20, 1054-1060.

Plantin, L., Olukoya, A.A., Ny, P. 2011: Positive health outcomes of fathers' involvement in pregnancy and childbirth. Paternal support: a scope literature review. Fathering: a Journal of Theory, Research and Practice about Men as Fathers 9, (1), 87-102.

Ramchandani, P.G., Domoney, J., Sethna, V., Psychogiou, L., Vlachos, H., Murray, L. 2013: Do early father-infant interactions predict the onset of externalising behaviours in young children: findings from a longitudinal cohort study. Journal of Child Psychology and Psychiatry 54, (1), 5664.

Salzmann-Erikson, M. \& Eriksson, H. 2013: Fathers sharing about early parental support in health-care - virtual discussion on an Internet Forum. Health and Social Care in the Community $21,(4), 381-390$.

Sherriff, N. and Hall, V. 2011: Engaging and supporting fathers to promote breastfeeding: a new role for Health Visitors? Scandinavian Journal of Caring Sciences 25, 467-475.

Sherriff, N. and Hall, V. 2014: Rhetoric or reality? Father support in promoting breastfeeding. International Journal of Birth and Parent Education 1, (4), 19-22.

Shribman, S. and Billingham, K. 2008: The Child Health Promotion Programme: Pregnancy and the First five Years of life: Update of Standard One (incorporating Standard Two) of the National Service Framework for Children, Young People and Maternity Services (2004). London: Department of Health.

Steen M., Downe S., Bamford N., Edozien L. 2012: Not-patient and not-visitor: a metasynthesis of fathers' encounters with pregnancy, birth and maternity care. Midwifery 28, 422-431.

StGeorge, J.M. and Fletcher, R.J. 2011: Father online: learning about fatherhood through the internet. The Journal of Perinatal Education 20, (3), 154-162. 
Tansella, M. and Thornicroft, G. 2009: Implementation science: understanding the translation of evidence into practice. The British Journal of Psychiatry 195, 283-285.

Taylor, J. and Daniel, B. 2000: The rhetoric vs the reality in child care and protection: ideology and practice in working with fathers. Journal of Advanced Nursing 31, (1), 12-19.

The Fatherhood Institute (2008) The Cost and Benefits of Active Fatherhood: Evidence and insights to inform the development of policy and practice.

Available at: http://www.fatherhoodinstitute.org/uploads/publications/247.pdf)

The Fatherhood institute (2010) The Fatherhood Institute Research Summary: Fathers and smoking. Available at:

http://www.fatherhoodinstitute.org/2007/fatherhood-institute-research-summary-fathers-andsmoking/

Tohotoa J., Maycock B., Hauck Y.L., Howat P., Burns S., Binns C.W. 2009: Dads make a difference: an exploratory study of paternal support for breastfeeding in Perth, Western Australia. International Breastfeeding Journal. Available at: http://www.internationalbreastfeeding journal.com/content/4/1/15

Yogman M.W., Kindlon D. 1995: Father involvement and cognitive, behavioural outcomes in preterm infants. Journal of the American Academy of Child \& Adolescent Psychiatry 34, (1), 58-

67.

Zanoni, L., Warburton, W., Bussey, K. \& McMaugh, M. 2013: Father as 'core business' in child welfare practice and research: an interdisciplinary review. Children and Youth Services Review 36, (7), 1055-1070.

\section{ACKNOWLEDGEMENT}

We would like to thank The Burdett Trust for Nursing for funding this project, and The Fatherhood Institute for the opportunity to collaborate with them, without which this research would not have been possible. Special thanks to the NHS Trusts, the Health Visitors and Community Practitioners who participated in the training. We would also like to thank Laura Scurlock-Evans for her advice concerning statistical measures. 